\title{
A Comparison of Brunei and Hong Kong - SAR Student Teachers' Self-efficacy in Implementing Inclusive Education Practices: Implications for Teacher Education
}

\author{
Kathleen Tait ${ }^{1}$ \& Lawrence Mundia ${ }^{2}$ \\ ${ }^{1}$ Department of Education Studies, Faculty of Social Sciences, Hong Kong Baptist University, Kowloon Tong, \\ Hong Kong \\ ${ }^{2}$ Sultan Hassanal Bolkiah Institute of Education, University of Brunei Darussalam, Bandar Seri Begawan, \\ Brunei Darussalam, Brunei \\ Correspondence: Kathleen Tait, Department of Education Studies, Faculty of Social Sciences, Hong Kong \\ Baptist University, Kowloon Tong, Hong Kong. E-mail: ktait@hkbu.edu.hk
}

Received: August 7, 2013 Accepted: October 22, 2013 Online Published: December 31, 2013

doi:10.5539/ass.v10n1p51 URL: http://dx.doi.org/10.5539/ass.v10n1p51

\begin{abstract}
The survey compared the scores of 159 (118 females) randomly selected Brunei and Hong Kong (Special Administrative Region) student teachers on the New General Self-efficacy Scale (NGSS); Self-efficacy in Implementing Inclusive Practices Scale (SIIPS); Sentiments, Attitudes and Concerns about Inclusive Education Scale (SACIES); and Inclusive Classroom Setting Scale (ICSS). The scales were reliable and valid for use with participants in both countries. Females scored significantly higher on NGSS than male counterparts. In addition, Brunei participants scored significantly higher on NGSS and SACIES than Hong Kong peers. Furthermore, the samples' scores differed significantly on NGSS and SACIES by participants' educational level with A-Level trainees scoring highest. Moreover, the majority of the participants generally scored high on all the scales. However, Two-Way ANOVA revealed only one independent variable (ICSS) with a significant main effect on SIIPS, the dependent variable. Also only one lower-order interaction variable (gender and educational level) had a significant joint effect on the dependent variable, SIIPS. Overall, the results indicate a need to increase self-efficacy in males and Hong Kong students. Extra attention and interventions ought to be directed to SACIES and ICSS variables. Mixed-methods research was recommended to gain more comprehensive insights.
\end{abstract}

Keywords: self-efficacy, inclusive education, inclusive class room, inclusive practices, student teachers

\section{Introduction}

Inclusive education refers to the notion that students with various degrees of special needs can be educated in regular schools along with their ordinary peers (Mundia, 2009). Although inclusive education has been operational for some time now in both Brunei and Hong Kong - Special Administrative Region of China (HK-SAR), there are still concerns about preparing effective teachers to meet its challenges (Bradshaw \& Mundia, 2006; Forlin, 2012; Tait \& Mundia, 2012). In Brunei, earlier research showed that more needed to be done to expose trainee teachers to the concept of disability and how this could be handled in classroom environments (Bradshaw \& Mundia, 2005; Haq \& Mundia, 2012). Mundia (2009) further proposed that school counselors could be used as resource persons to enhance the capabilities of regular teachers under the ongoing implementation of inclusive education in Brunei Darussalam. Since teaching was a demanding task that requires highly self-motivated professionals, the whole teacher education program in Brunei needed to be reformed to train people with deep interest in teaching to guarantee teacher effectiveness in using inclusive practices within inclusive settings (Mundia, 2009; Mundia, 2012a). The training of effective teachers and other professionals at universities in Brunei is now considered a very important undertaking under the ongoing tertiary education reforms (Mundia, 2012b). In addition, recent research further indicated that Brunei teachers need to know more about how to meaningfully assess students' problems and provide appropriate interventions in key subjects such as mathematics and English to resolve the students' learning problems (Mundia, 2010a; Mundia, 2012c; Hamid et al., 2013; Matzin et al., 2013; Shahrill et al., 2013). With implementation of both inclusive education and curriculum reforms, teachers in Brunei now need more diverse skills to teach effectively (Mundia, 2009; Mundia, 
2010b). However, due to insufficient research, Brunei student teachers' self-efficacy in implementing inclusive education practices is not fully known. Bandura (1977) defined self-efficacy (SE) as the cognitive belief that one is competent at a particular task. Legge et al. (2005) and Hill (2009) differentiated self-efficacy from self-esteem (having positive and negative feelings about one's ability), achievement motivation (one's need or desire to be competent and do well), and general self-confidence (positive and negative perceptions of oneself). Instead, these authors argue that self-efficacy focuses on thought processes, actual self-perception of current competence, and is situation specific. Legge et al (2005) and Hill (2009) believe that several factors contribute to self-efficacy including: (1) one's own past performance; (2) verbal feedback and persuasion; (3) the observation of others' performance; (4) realistic or appropriate goal setting; and (5) positive and constructive feedback. Part of the problem in Brunei may be attributed to lack of suitable research instruments to use in assessing the needs of both trainee and serving teachers (Mundia, 2010c; Mundia 2011a). Western research instruments that are reliable, valid and unbiased for use in Brunei still need to be identified. Furthermore, some student teachers also have psychological and academic problems of their own such as anxiety, depression, stress, and mental health issues (see Mundia, 2010d; Mundia, 2010e; Mundia, 2011b; Haq \& Mundia, 2013) that may impact negatively on their self-efficacy. There are some concerns that these problems are often not resolved adequately and satisfactorily by trainee teachers due to limitations in their coping abilities and this tends to harm further their self-efficacy (see Mundia, 2010f). It appears that self-efficacy might also be facilitated if teachers had the ability or capacity to provide counseling services to students with high support needs (see Shahrill \& Mundia, 2014). In Brunei, recent research has shown that trainee teachers of both genders have the will to work together amicably (Mahalle et al., 2014). In view of this, it might be easy for serving teachers without counseling skills to make referrals of needy students to colleagues with such skills.

\section{Objectives of the Study}

The overall goal of the present study was to identify areas needing psychological and educational interventions to help the student teachers to improve their self-efficacy in implementing inclusive education in Brunei and Hong Kong. Based on this, the specific purpose of the present study was three-fold, namely to:

1) Measure student teachers' general self-efficacy; specific self-efficacy in implementing inclusive practices; sentiments, attitudes and concerns about inclusive education; and views on inclusive classroom settings;

2) Compare the student teachers' scores on the above variables by gender, country, and participants' educational level; and

3) Determine the amount of general self-efficacy; concerns about inclusive education; and inclusive classroom views in student teachers with different levels of self-efficacy in implementing inclusive practices.

\section{Method}

The study used the field survey approach to investigate the problem. This research design differs from the postal, online and telephone surveys in that investigators went out in the field (relevant educational institutions in the present study) to collect the data either personally or using research assistants. The rationale and justification for employing this research strategy was two-fold. First, we wanted to involve as many trainee teachers in the study as possible. Second, it was then possible to give on-the-spot assistance to respondents who needed help to complete the data collection instruments correctly thereby increasing the number of usable returns.

\section{Sample}

Participants in the study were drawn randomly from within all student teachers in two universities (one in Brunei and the other in Hong Kong). Initially, a total of 167 questionnaires were distributed to chosen student teachers but only 159 submitted properly completed and usable protocols. The remaining 8 students were excluded from the study for a variety of reasons including declining to participate in the study by not returning the questionnaires, completing the scales incorrectly by endorsing item scales with central and extremity response biases, and having many missing values. The participants' bio-data (gender, educational level, and age) are presented in Table 1 . 
Table 1. Participants' demographic data $(\mathrm{N}=159)$

\begin{tabular}{|c|c|c|c|c|c|}
\hline Variable & Group & Frequency & \multicolumn{2}{|c|}{$\%$} & \\
\hline \multirow[t]{6}{*}{ Gender } & All females & 118 & \multicolumn{2}{|c|}{74} & \\
\hline & All males & 41 & \multicolumn{2}{|c|}{26} & \\
\hline & Brunei females & 70 & \multicolumn{2}{|c|}{44} & \\
\hline & Brunei males & 14 & \multicolumn{2}{|c|}{9} & \\
\hline & HK females & 48 & \multicolumn{2}{|c|}{30} & \\
\hline & HK males & 27 & \multicolumn{2}{|c|}{17} & \\
\hline \multirow[t]{6}{*}{ Age } & & Mean & \multicolumn{2}{|c|}{ SD } & \\
\hline & All participants & 23.786 & \multicolumn{2}{|c|}{3.450} & \\
\hline & All females & 23.237 & \multicolumn{2}{|c|}{3.095} & \\
\hline & All males & 25.365 & \multicolumn{2}{|c|}{3.941} & \\
\hline & Brunei students & 21.892 & \multicolumn{2}{|c|}{1.975} & \\
\hline & HK students & 25.906 & \multicolumn{2}{|c|}{3.522} & \\
\hline \multirow[t]{6}{*}{ Qualification } & & Frequency & $\%$ & Brunei & $\mathrm{HK}(\mathrm{SAR}) *$ \\
\hline & A-Level/Cert Ed & 92 & 58 & 80 & 12 \\
\hline & Undergrad. Degree & 12 & 8 & 1 & 11 \\
\hline & Honors degree & 35 & 22 & 3 & 32 \\
\hline & Postgraduate/Masters & 18 & 11 & 0 & 18 \\
\hline & Others & 2 & 1 & 0 & 2 \\
\hline
\end{tabular}

* HK(SAR) $=$ Hong Kong Special Administrative Region of China)

\section{Instruments}

We used five instruments to collect research data and these were: the researcher-constructed demographical questionnaire that collected biographical data (gender, age and educational level); the New General Self-efficacy Scale, NGSS (Chen et al., 2001); original and longer version of Self-efficacy in Implementing Inclusive Practices Scale, SIIPS (Deppeler, Loreman, \& Sharma, 2005; Sharma, Loreman, \& Forlin, 2012); Sentiments, Attitudes and Concerns about Inclusive Education Scale, SACIES (Loreman et al., 2007), and Inclusive Classroom Setting Scale, ICSS (self-constructed by the researchers with items adapted from Loreman et al., 2007). The NGSS is an 8-item (5-point Likert-tye scale) that measures self-efficacy in any area of specialization. Similarly, the SIIPS (29 items) and the SACIES (23 items) are all 5-point Likert-type scales measuring concepts depicted or embedded in their titles. However, the ICSS (12 items) is a bi-polar adjective scale with the following extreme ends: 1 None and 9 Extensive. This scale measures the participants' views about the inclusive classroom environment. The descriptive statistics and reliability coefficients for the four rating inventories are presented in Table 2.

Table 2. Reliability of the data collection instruments $(\mathrm{N}=159)$

\begin{tabular}{lllllc}
\hline Scale & Items & Mean & $\begin{array}{l}\text { SE } \\
\text { mean }\end{array}$ & SD & Alpha \\
\hline $\begin{array}{l}\text { New General Self-Efficacy Scale } \\
\text { (NGSS) }\end{array}$ & 8 & 23.767 & 0.597 & 7.535 & 0.959 \\
Self-efficacy in Implementing Inclusive Practices Scale (SIIP) & 29 & 127.239 & 1.163 & 14.639 & 0.938 \\
Sentiments, Attitudes and Concerns about Inclusive Education & 23 & 57.854 & 0.597 & 7.448 & 0.757 \\
Scale (SACIES) & & & & & \\
Inclusive Classroom Setting Scale (ICSS) & 12 & 43.723 & 1.727 & 18.039 & 0.910 \\
\hline
\end{tabular}


The correlations in Table 3 may be interpreted in many ways. The low and non-significant correlations suggest that the scales are measures of different constructs and do not replicate each other. For these scales, the correlations provide good quantitative evidence for the scales' discriminant validity. The low but significant correlations imply that the scales (to a small extent) might be overlapping and measuring the same construct but the amount of duplication or common variance $\left(\mathrm{r}^{2}\right)$ is little and negligible. The paired scales can thus be said to have satisfactory discriminant validity and low convergence validity. In addition, the questionnaire scores used in the present study were considered to have had good ecological validity in that all data were collected in the participants' respective university environments.

Table 3. Convergence and discriminant validity of the data collection instruments $(\mathrm{N}=159)$

\begin{tabular}{lllll}
\hline & Scale & 1 & 2 & 3 \\
\hline 1. & NGSS $^{\text {a }}$ & 1 & & \\
2. & SIIPS $^{b}$ & 0.149 & 1 & \\
3. & SACIES $^{\text {c }}$ & $0.592 * *$ & 0.105 & 1 \\
4. & ICSS $^{\text {d }}$ & 0.134 & $0.322 *$ & -0.037 \\
\hline
\end{tabular}

${ }^{a}$ New General Self-efficacy Scale

${ }^{\mathrm{b}}$ Self-efficacy in Implementing Inclusive Practices Scale

${ }^{c}$ Sentiments, Attitudes and Concerns about Inclusive Education Scale

${ }^{\mathrm{d}}$ Inclusive Classroom Setting Scale

$* \mathrm{p}<.05$ (2-tailed)

$* * \mathrm{p}<.01(2$-tailed $)$

\section{Data Analysis}

The quantitative data were analyzed by both descriptive statistics (frequencies, percentages, mean standard error of the mean, standard deviation, and quartiles) and inferential statistics (t-tests for independent samples incorporating ANCOVA F, Pearson's correlations, One-Way ANOVA, and Univariate Analysis of Variance or Two-Way ANOVA), and non-parametric statistics (chi-square). The rationale and justification for using these techniques is two-fold. First, the procedures were deemed to be appropriate for addressing the research objectives. Second, the data were obtained from a random sample and there was no violation of the statistical assumptions.

\section{Procedures}

Prior to collecting the data, the participants were told about the purpose and objectives of the study. No deception was involved in the study. In addition, the participants were told both verbally and in writing about the ethical conditions or requirements for being involved in the study. The discussion on this topic centered on issues of voluntary participation, privacy, anonymity, confidentiality, physical and psychological harm, debriefing, and informed consent. Students were given ample time to reflect on and withdraw from the study if they felt uncomfortable with the research's purpose and objectives. The participants voluntarily agreed to participate in the study. With regard to English language problems, the meanings of difficult English words, sentences and phrases on the instruments were verbally explained to the participants. Furthermore, students at the participants' university take most courses in English language and have participated in many research studies that required them to complete self-report scales / questionnaires in English. The researchers therefore deemed it not necessary to translate the instruments into Bahasa Melayu (Brunei's mother tongue and official language). The study met the ethical requirements for using human participants in research stipulated by the participants' university, the Government of Brunei, and the Helsinki Declaration.

\section{Results}

The findings of the study are presented below according to the three main objectives of the investigation.

General self-efficacy; specific self-efficacy in implementing inclusive practices; sentiments, attitudes and concerns about inclusive education; and inclusive classroom setting views

The overall mean scores, standard errors of the means and standard deviations for the whole sample on the four 
scales are presented in Table 2. However, the median scores and coefficients of skewness (not included in Table 2) were as follows: NGSS (Mdn $=24.000$; Skew $=-0.052)$; SIIPS $(\mathrm{Mdn}=129.000$; Skew $=-0.210)$; SACIES $(\mathrm{Mdn}=57.000 ;$ Skew $=0.228)$; and ICSS $(\mathrm{Mdn}=50.000$; Skew $=0.438)$. Although the raw scores were not standardized, a direct comparison of the means and medians reveals that only the mean for the SACIES scale was slightly larger than its median counterpart. The differences between the means and the medians were small and insignificant. In addition only scores for two scales (NGSS and SIIPS) were left or negatively skewed but the skew coefficients were small. These statistics imply that the majority of the participants scored around these scales' two central tendency measures (mean and median).

Comparison of the student teachers' scores on the four scales by gender, institution, and participants' educational level

As reported in Table 4, the two genders' scores differed significantly only on the NGSS scale where females scored higher than their male counterparts.

Table 4. Means, standard deviations and T-values by gender $(\mathrm{N}=159)$

\begin{tabular}{|c|c|c|c|c|c|c|c|}
\hline \multirow[t]{2}{*}{ Scale $\dagger$} & \multicolumn{2}{|c|}{ Females $(\mathrm{n}=118)$} & \multicolumn{2}{|c|}{ Males $(\mathrm{n}=41)$} & \multirow{2}{*}{$\begin{array}{l}\text { ANCOVA } \\
\text { F }\end{array}$} & \multirow{2}{*}{$\begin{array}{l}\mathrm{T} \\
(d f=157)\end{array}$} & \multirow{2}{*}{$\begin{array}{l}\text { P-2 tailed } \\
\text { (Effect Size) }\end{array}$} \\
\hline & Mean & SD & Mean & SD & & & \\
\hline NGSS & 24.644 & 7.403 & 21.243 & 7.428 & $0.000 n s$ & 2.531 & $\begin{array}{l}0.012 * * \\
(0.039)\end{array}$ \\
\hline SIIPS & 127.533 & 14.861 & 126.243 & 14.236 & $0.254 n s$ & 0.484 & $\begin{array}{l}0.629 \\
(0.001)\end{array}$ \\
\hline SACIES & 58.144 & 7.752 & 56.439 & 6.800 & $3.834 *$ & 1.250 & $\begin{array}{l}0.213 \\
(0.010)\end{array}$ \\
\hline ICSS & 49.330 & 23.300 & 52.341 & 16.707 & $7.738^{* *}$ & -0.762 & $\begin{array}{l}0.447 \\
(0.004)\end{array}$ \\
\hline
\end{tabular}

$\dagger$ For full scale names see bottom of Table 3

$* \mathrm{p}<.05$ (2-tailed)

$* * \mathrm{p}<.01$ (2-tailed)

ns $=$ not significant

Only two significant differences were obtained by country on the NGSS and SACIES scales. For both of these, Brunei students scored much higher than their Hong Kong peers (see Table 5).

Table 5. Means, standard deviations and T-values by institution $(\mathrm{N}=159)$

\begin{tabular}{|c|c|c|c|c|c|c|c|}
\hline \multirow[t]{2}{*}{ Scale $\dagger$} & \multicolumn{2}{|c|}{ Brunei $(n=84)$} & \multicolumn{2}{|c|}{ HK-SAR $(n=75)$} & \multirow{2}{*}{$\begin{array}{l}\text { ANCOVA } \\
\text { F }\end{array}$} & \multirow{2}{*}{$\begin{array}{l}\mathrm{T} \\
(d f=157)\end{array}$} & \multirow{2}{*}{$\begin{array}{l}\text { P-2 tailed } \\
\text { (Effect Size) }\end{array}$} \\
\hline & Mean & SD & Mean & SD & & & \\
\hline NGSS & 29.904 & 4.034 & 16.893 & 3.512 & $0.326 n s$ & 21.566 & $\begin{array}{l}0.000 * * \\
(0.748)\end{array}$ \\
\hline SIIPS & 129.226 & 14.673 & 124.933 & 14.425 & $0.121 n s$ & 1.856 & $\begin{array}{l}0.065 \\
(0.021)\end{array}$ \\
\hline SACIES & 62.833 & 5.801 & 51.960 & 4.491 & $2.191 n s$ & 13.099 & $\begin{array}{l}0.000 * * \\
(0.522)\end{array}$ \\
\hline ICSS & 50.773 & 25.327 & 49.360 & 17.099 & $10.111 * *$ & 0.407 & $\begin{array}{l}0.684 \\
(0.001)\end{array}$ \\
\hline
\end{tabular}

$\dagger$ see Table 3 for full scale names

$* * \mathrm{p}<.01$ (2-tailed)

ns $=$ not significant 
In terms of the participants' educational levels, two significant differences were obtained on NGSS and SACIES scales (Table 6). In both of these instances, student teachers with A-Level (Year 13) educational background scored much higher than fellow trainee with higher entry qualifications

Table 6. Means, standard deviations and $\mathrm{F}$-values by educational level $(\mathrm{N}=159)$

\begin{tabular}{|c|c|c|c|c|c|c|c|c|}
\hline Scale $\dagger$ & $\begin{array}{l}\text { A-Level } \\
\mathrm{n}=92 \\
\text { Mean } \\
\text { (SD) }\end{array}$ & $\begin{array}{l}\text { Undergraduate } \\
\mathrm{n}=12 \\
\text { Mean } \\
\text { (SD) }\end{array}$ & $\begin{array}{l}\text { Honors } \\
\mathrm{n}=35 \\
\text { Mean } \\
(\mathrm{SD})\end{array}$ & $\begin{array}{l}\text { Masters } \\
\mathrm{n}=18 \\
\text { Mean } \\
\text { (SD) }\end{array}$ & $\begin{array}{l}\text { Others } \\
\mathrm{n}=2 \\
\text { Mean } \\
\text { (SD) }\end{array}$ & $\begin{array}{l}\mathrm{F} \\
(d f=4 ; 158)\end{array}$ & $\begin{array}{l}P \\
\text { (2-tailed) }\end{array}$ & Eta Squared \\
\hline NGSS & $\begin{array}{l}28.206 \\
(5.927)\end{array}$ & $\begin{array}{l}16.750 \\
(6.062)\end{array}$ & $\begin{array}{l}17.828 \\
(4.630)\end{array}$ & $\begin{array}{l}16.000 \\
(3.678)\end{array}$ & $\begin{array}{l}18.000 \\
(1.414)\end{array}$ & 37.216 & $0.000 * *$ & 0.492 \\
\hline SIIPS & $\begin{array}{l}128.260 \\
(15.510)\end{array}$ & $\begin{array}{l}131.666 \\
(13.005)\end{array}$ & $\begin{array}{l}124.342 \\
(13.281)\end{array}$ & $\begin{array}{l}125.777 \\
(13.837)\end{array}$ & $\begin{array}{l}114.500 \\
(2.121)\end{array}$ & 1.152 & 0.334 & 0.029 \\
\hline SACIES & $\begin{array}{l}61.315 \\
(6.881)\end{array}$ & $\begin{array}{l}57.000 \\
(6.281)\end{array}$ & $\begin{array}{l}52.342 \\
(3.984)\end{array}$ & $\begin{array}{l}51.611 \\
(5.054)\end{array}$ & $\begin{array}{l}44.500 \\
(4.949)\end{array}$ & 21.646 & $0.000 * *$ & 0.360 \\
\hline ICSS & $\begin{array}{l}50.934 \\
(24.735)\end{array}$ & $\begin{array}{l}45.333 \\
(22.463)\end{array}$ & $\begin{array}{l}48.685 \\
(16.003)\end{array}$ & $\begin{array}{l}52.555 \\
(14.971\end{array}$ & $\begin{array}{l}43.500 \\
(24.748)\end{array}$ & 0.312 & 0.870 & 0.008 \\
\hline
\end{tabular}

$\dagger$ see Table 3 for names of scales

$* * \mathrm{p}<.01$

\section{Multivariate relationship between eleven independent variables and one dependent variable}

Table 7 shows the relationship between seven single independent variables, two lower-order (two-factor) interaction variables, and one higher-order (three-factor) interaction variable with self-efficacy in implementing inclusive practices as the dependent variable. The analysis yielded only one significant main or separate effect (ICSS, $\mathrm{p}<.01$ ) and one significant lower-order interaction or joint effect (gender and educational level, $\mathrm{p}<.05$ ).

Table 7. Univariate analysis of variance using self-efficacy in implementing inclusive practices (SIIP) as a dependent variable $(\mathrm{N}=159)$

\begin{tabular}{lllllll}
\hline Source & $\begin{array}{l}\text { Sum of Squares } \\
\text { (Type III) }\end{array}$ & $\mathrm{d} f$ & Mean Square & $\mathrm{F}$ & Sig. & $\begin{array}{l}\text { Partial Eta } \\
\text { Squared }\end{array}$ \\
\hline Age & 31.834 & 1 & 31.834 & 0.174 & 0.677 & 0.001 \\
NGSS & 10.848 & 1 & 10.848 & 0.059 & 0.808 & 0.000 \\
SACIES & 0.097 & 1 & 0.097 & 0.001 & 0.982 & 0.000 \\
ICSS & 3953.166 & 1 & 3953.166 & 21.647 & $0.000 * *$ & 0.133 \\
Gender & 148.592 & 1 & 148.592 & 0.814 & 0.369 & 0.006 \\
Ed Level $\dagger$ & 462.393 & 4 & 115.598 & 0.633 & 0.640 & 0.018 \\
Country & 28.124 & 1 & 28.124 & 0.154 & 0.695 & 0.001 \\
Gender * Ed Level & 1809.981 & 3 & 603.327 & 3.304 & $-0.022^{*}$ & 0.066 \\
Gender * Country & 168.991 & 1 & 168.991 & 0.925 & 0.338 & 0.007 \\
Ed Level * Country & 435.201 & 2 & 217.601 & 1.192 & 0.307 & 0.017 \\
Gender * Ed Level * Country & 85.972 & 1 & 85.972 & 0.471 & 0.494 & 0.003 \\
Error & 25749.427 & 141 & 182.620 & & & \\
Total & 2606645.000 & 159 & & & & \\
\hline
\end{tabular}

Model: $\mathrm{F}(18,159)=785.144, \mathrm{P}<.01 ; \mathrm{R}$ Squared $=0.990$ (Adjusted R Squared $=0.989)$

$\dagger$ EdLevel $=$ Educational Level

$* \mathrm{P}<.05$ (two-tailed)

$* * \mathrm{P}<.01$ (two-tailed) 
General self-efficacy; concerns about inclusive education; and inclusive classroom views in student teachers with different levels of self-efficacy in implementing inclusive practices

According to Table 8, there were more students of both genders whose total scores were within the bottom and top categories of the score distributions for the four scales. In this table, a participant was placed in the bottom category if her / his total score fell in the $1^{\text {st }}$ quartile of the score distribution. Participants were put in the middle and top groups if their total scores were in the $2^{\text {nd }}$ and 3 rd quartiles respectively. However, we noted a big difference in the way these frequencies were unevenly distributed by country (see the pattern or trend in Table 8). Brunei participants scored mostly in the high group on all the four scales. On the other hand, Hong Kong student teachers mostly scored low on two variables (NGSS and SACIES) but high on the other two scales (SIIPS and ICSS).

Table 8. Frequency of cases by scale, score categories, gender and county $(\mathrm{N}=159)$

\begin{tabular}{lllllll}
\hline Scale $\dagger$ & Score categories & All females & All males & All Brunei & All HK(SAR) & All groups \\
\hline \multirow{3}{*}{ NGSS } & & F & F & F & F & F \\
& Bottom & 28 & 19 & 1 & 46 & 47 \\
& Middle & 25 & 9 & 6 & 28 & 34 \\
& Top & 65 & 13 & 77 & 1 & 78 \\
SIIPS & Bottom & 21 & 10 & 16 & 25 & 41 \\
& Middle & 26 & 12 & 21 & 17 & 38 \\
& Top & 61 & 19 & 47 & 33 & 80 \\
SACIES & Bottom & 32 & 11 & 3 & 40 & 43 \\
& Middle & 24 & 15 & 11 & 28 & 39 \\
& Top & 62 & 15 & 170 & 7 & 77 \\
& Bottom & 36 & 5 & 23 & 18 & 41 \\
& Middle & 28 & 11 & 22 & 17 & 39 \\
& Top & 54 & 25 & 39 & 40 & 79 \\
\hline
\end{tabular}

$\dagger$ for scale names see Table 3

${ }^{\mathrm{a}} \mathrm{HK}(\mathrm{SAR})=$ Hong Kong $($ Special Administrative Region of China)

Relationship in performance between NGSS, SACIES, and ICSS versus performance in SIIPS

We obtained two significant differences in Table 9. The number of participants who scored in the top levels of SIIPS and NGSS was much higher than the frequencies for the other score categories. This pattern was also observed between ICSS and SIIPS (see Table 9).

Table 9. Frequency of cases by score categories in NGSS, SACIES and ICSS Vs SIIPS (N=159)

\begin{tabular}{lllllll}
\hline Scale $\dagger$ & Score categories & \multicolumn{2}{l}{ SIIPS score categories } & & Chi-square & P \\
\hline \multirow{3}{*}{ NGSS } & & Bottom & Middle & Top & $(d f=4)$ & $(2$-tailed $)$ \\
& Bottom & 11 & 7 & 29 & 24.691 & $0.000^{* *}$ \\
& Middle & 18 & 10 & 6 & & \\
\multirow{5}{*}{ SACIES } & Top & 12 & 21 & 45 & & 0.577 \\
& Bottom & 15 & 8 & 20 & 2.889 & \\
& Middle & 8 & 10 & 21 & & $0.002^{* *}$ \\
& Top & 18 & 20 & 39 & & \\
& Bottom & 20 & 9 & 12 & 16.766 & \\
& Middle & 7 & 11 & 21 & & \\
& Top & 14 & 18 & 47 & & \\
\hline
\end{tabular}

$\dagger$ Full scales names are presented under Table 3

$* * \mathrm{p}<.01$ (2-tailed) 


\section{Discussion}

The present study found a few statistically significant differences in the results. In this section, we labor to offer plausible explanations for both the main findings and associated practical implications.

In general, an examination of measures of central tendency revealed that the participants tended to score high on the four scales. For example, two of the scales (NGSS and SIIPS) had negative coefficients of skewness while the other two (SACIES and ICSS) had large median scores. These positive attitudes are consistent with findings in Haq and Mundia's (2012) study in which trainee teachers were observed to have positive attitudes toward students with mild-to-moderate disabilities but whose attitudes to learners with severe disabilities and high support needs were questionable. This finding suggests that teacher education programs in both instituitons (Brunei and Hong Kong-SAR) need to assist student teachers to increase their self-efficacy (both general and specific) in implementing inclusive education practices. The ways or means for achieving this were outside the scope and objectives of the present study but they must be found to address the problem. Findings from previous research described above (Legge et al., 2005; Hill, 2009) suggested that self-efficacy was related to: (1) one's own past performance; (2) verbal feedback and persuasion; (3) the observation of others' performance; (4) realistic or appropriate goal setting; and (5) positive and constructive feedback. These are some of the areas to which attention, psychological and educational interventions could be directed to by teacher education programs. There are a number of significant differences in the participants' performance on various scales used in the present study. The major significant differences were by gender (see Table 4), country (Table 5), and respondents' educational level (Table 6). It is hoped that the ongoing teacher education reforms in both Brunei Darussalam and Hong King - SAR documented in the relevant literature for previous studies (see Mundia, 2009; Mundia, 2010b; Mundia, 2012a; Mundia, 2012b; Forlin, 2012; Tait \& Mundia, 2012) will address these issues to narrow the differences or gaps. In addition, this also implies that teacher education programs in the two institutions (Brunei and Hong Kong-SAR) need to design and implement training programs that can boost self-efficacy in implementing inclusive education practices in all categories of student teachers. Among all the variables investigated, ICSS was the only one that had a significant main or separate effect $(p<.01)$ for explaining the student teachers' self-efficacy in implementing inclusive education practices as indicated in Table 7. However, this was associated with a small but reasonable effect size (Partial $\eta 2=0.133$ ). We also obtained one lower-order significant interaction (joint) effect between gender and educational level of the participant ( $\mathrm{p}$ $<.05$ ) although it had only a tiny and non-exciting effect size. It therefore seems that any program that is intended to increase student teachers self-efficacy in implementing inclusive education practices should incorporate elements of these three variables (ICSS, gender and educational level. Evidence from the present study (Tables 8-9) also showed that teacher trainees who scored high on NGSS and ICSS scales also tended to score high on the SIIPS scale. This pattern or trend of scores suggests that general self-efficacy and positive views of the inclusive classes might be good predictors of specific self-efficacy in implementing inclusive education practices. However, the prediction aspect was not investigated in the present study. The notion of prediction was only supported by the correlation between ICSS and SIIPS in Table 3. The other variable, NGSS, was more strongly related to SACIES (Table 3). From this, it appears that increasing general self-efficacy might improve positive attitudes to and lower concerns about inclusive education in student teachers. SACIES scores were too high for Brunei student teachers (Table 5) and A-level entrants to teacher training who were mainly Bruneians (see Table 1 and Table 6).

\section{Conclusion}

Based on the findings from the present study, we conclude that there was overwhelming evidence to support the suggestion for increasing self-efficacy among the participants. The key intervention required needs to create and maintain positive attitudes and practical skills in student teachers for implementing inclusive education practices. We recommend further mixed-methods research to gain additional insights into the problem and its possible solutions.

\section{Limitations}

The present study was informed by three main limitations. First, as a survey the results cannot establish cause-and-effect relationships in the variables investigated. Second, a qualitative interview component is missing but was necessary to triangulate findings from the quantitative survey. Third, no attempt was made to obtain criterion-related validity of the scales used due to concerns that student teacher participants were too busy with examinations preparations towards the end of the semester and did not have a lot of time to complete many questionnaires at the time of data collection. 


\section{References}

Bandura, A. (1977). Self-efficacy: Toward a unifying theory of behavioral change. Psychological Review, 84, 191-215. http://dx.doi.org/10.1037/0033-295X.84.2.191

Bradshaw, L., \& Mundia, L. (2005). Understanding pre-service teachers' construct of disability: A metacognitive process. Disability and Society, 20(5), 563-574. http://dx.doi.org/10.1080/09687590500156329

Bradshaw, L., \& Mundia, L. (2006). Attitudes to and concerns about inclusive education: Bruneian inservice and pre-service teachers. International Journal of Special Education, 21(1), 35-41.

Chen, G., Gully, S. M., \& Eden, D. (2001). Validation of a new general self-efficacy scale. Organizational Research Methods, 4(1), 62-83. http://dx.doi.org/10.1177/109442810141004

Deppeler, J., Loreman, T., \& Sharma, U. (2005) Improving inclusive practices in secondary schools: Moving from specialist support to supporting learning communities. Australasian Journal of Special Education, 29(2), 117-127. http://dx.doi.org/10.1080/1030011050290204

Forlin, C. I. (2012). Future directions for inclusive teacher education: An international perspective. Hong Kong: Routledge/Francis \& Taylor.

Hamid, M. H. S., Shahrill, M., Matzin, R., Mahalle, S., \& Mundia, L. (2013). Barriers to mathematics achievement in Brunei secondary school students: Insights into the roles of mathematics anxiety, self-esteem, proactive coping, and test stress. International Education Studies, 6(11), 1-14.

Haq, F. S., \& Mundia, L. (2012). Comparison of Brunei pre-service student teachers' attitudes to inclusive education and specific disabilities: Implications for teacher education. Journal of Educational Research, 105(5), 366-374. http://dx.doi.org/10.1080/00220671.2011.627399

Haq, F. S., \& Mundia, L. (2013). The assessment of psychological distress in Brunei female, mature age and part-time student teachers: Counseling implications. European Journal of Educational Studies, 5(1), 87-100.

Hill, G. (2009). AS and A level psychology in diagrams. Oxford: Oxford University Press.

Legge, K., Harari, P., Sherry, L., \& Gadson, S. (2005). Psychology A2 for OCR. Oxford: Heinemann.

Loreman, T., Earle, C., Sharma, U., \& Forlin, C. (2007). The development of an instrument for measuring re-service teachers' sentiments, attitudes, and concerns about inclusive education. International Journal of Special Education, 22(2), 150-159.

Mahalle, S., Matzin, R., Hamid, M. H. S., Shahrill, M., \& Mundia, L. (2014). Brunei Student Teachers' Selected Personal Attributes, Attitudes to Women and Interpersonal Trust: Brief Psychological Report. Asian Social Science, $10(1)$.

Matzin, R., Shahrill, M., Mahalle, S., Hamid, M. H. S., \& Mundia, L. (2013). A Comparison of Learning Styles and Study Strategies Scores of Brunei Secondary School Students by Test Anxiety, Success Attributions, and Failure Attributions: Implications for Teaching At-risk and Vulnerable Students. Review of European Studies, 5(5), 119-127. http://dx.doi.org/10.5539/res.v5n5p119

Mundia, L. (2009). Implementation of inclusive education in Brunei Darussalam: Review of possible implications on school counselors. Electronic Journal for Inclusive Education, 2(4).

Mundia, L. (2010a). Problems in learning mathematics: Comparison of Brunei junior high school students in classes with and without repeaters. Journal of Mathematics Research, 2(3), 150-160.

Mundia, L. (2010b). Implementation of SPN21 curriculum in Brunei Darussalam: A review of selected implications on school assessment reforms. International Education Studies, 3(2), 119-129.

Mundia, L. (2010c). The suitability of the EPQ-R short scale for counseling Brunei student teachers when administered in English and Malay languages. Compare: Journal of Comparative and International Education, 40(5), 641-658. http://dx.doi.org/10.1080/03057920903478654

Mundia, L. (2010d). Prevalence of depression, anxiety and stress in Brunei student teachers. Internet Journal of Mental Health, 6(2).

Mundia, L. (2010e). The status of a trainee teacher with mental health problems: Dilemmas on inclusion and exclusion in higher education. Global Journal of Health Science, 2(2), 172-183.

Mundia, L. (2010f). Brunei trainee teachers' coping strategies for stressful situations. International Journal of 
Psychological Studies, 2(1), 79-88.

Mundia, L. (2011a). Social desirability, non-response bias and reliability in a long self-report measure: Illustrations from the MMPI-2 administered to Brunei student teachers. Educational Psychology: An International Journal of Experimental Educational Psychology, 31(2), 207-224. http://dx.doi.org/10.1080/01443410.2010.545049

Mundia, L. (2011b). Effects of psychological distress on academic achievement in Brunei student teachers: Identification challenges and counseling implications. Higher Education Studies, 1(1), 51-63. http://dx.doi.org/10.5539/hes.v1n1p51

Mundia, L. (2012a). Policy changes in Brunei teacher education: Implications for the selection of trainee teachers. The Education Forum, 76(3), 326-342. http://dx.doi.org/10.1080/00131725.2012.682489

Mundia, L. (2012b). Assessment of GenNEXT learning outcomes at the University of Brunei Darussalam: A qualitative review of selected opportunities, benefits and challenges in human resource development. Journal of International Education and Leadership, 2(3).

Mundia, L. (2012c). The Assessment of Mathematics Learning Difficulties in a Primary Grade 4 Child with High Support Needs: Mixed Methods Approach. International Electronic Journal of Elementary Education, 4(2), 347-366.

Shahrill, M., \& Mundia, L. (2014). Coping Behavior of International Late Adolescent Students in Selected Australian Educational Institutions. Global Journal of Health Science, 6(1), 76-91.

Shahrill, M., Mahalle, S., Matzin, R., Hamid, M., Sheikh, H., \& Mundia, L. (2013). A Comparison of Learning Styles and Study Strategies used by Low and High Math Achieving Brunei Secondary School Students: Implications for Teaching. International Education Studies, 6(10), 39-46. http://dx.doi.org/10.5539/ies.v6n10p39

Sharma, U., Loreman, T., Forlin, C. (2012). Measuring teacher efficacy to implement inclusive practices. Journal of Research in Special Educational Needs, 12(1), 12-21. $\mathrm{http}: / / \mathrm{dx}$. doi.org/10.1111/j.1471-3802.2011.01200.x

Tait, K., \& Mundia, L. (2012). Preparing teachers to meet the challenges of inclusive education in Negara Brunei Darussalam. In C. I. Forlin (Ed.), Future directions for inclusive teacher education: An international perspective (pp. 60-69). Hong Kong: Routledge/Francis \& Taylor.

\section{Copyrights}

Copyright for this article is retained by the author(s), with first publication rights granted to the journal.

This is an open-access article distributed under the terms and conditions of the Creative Commons Attribution license (http://creativecommons.org/licenses/by/3.0/). 